\title{
Growth hormone and tesamorelin in the management of HIV-associated lipodystrophy
}

\author{
This article was published in the following Dove Press journal: \\ HIVIAIDS - Research and Palliative Care \\ 8 July 2011 \\ Number of times this article has been viewed
}

\section{Roger Bedimo}

Infectious Disease section, VA North Texas Health Care System, TX, USA
Correspondence: Roger Bedimo 4500 South Lancaster Road,

Dallas, TX 75208, USA

Tel + I 2148570397

Fax + I 214302 I433

Email roger.bedimo@va.gov

\begin{abstract}
HIV-infected patients on highly active antiretroviral therapy (HAART) develop a complex of body composition changes known, including peripheral fat loss (lipoatrophy) and central fat accumulation (lipohypertrophy). These changes may cause significant patient distress, which could in turn interfere with adherence to antiretroviral therapy. Treatment options - including antiretroviral switch, insulin sensitizers, and surgical approaches - have been associated with limited success and potential complications. The observation that low growth hormone levels are associated with central fat accumulation among HIV patients has led to the development of tesamorelin (a growth hormone releasing hormone analog) for the management of central fat accumulation. Randomized controlled trials have shown that administration of tesamorelin is safe and effective in reducing central fat accumulation among HIV-infected patients. This effect is transient, however, and its association with improved cardiovascular risk remains unclear.
\end{abstract}

Keywords: HAART, HIV, tesamorelin, lipodystrophy

\section{Introduction}

The introduction and widespread use of protease inhibitors (PI) in the context of highly active antiretroviral therapy (HAART) in the mid-1990s has been associated with a dramatic reduction in the mortality of HIV-infected patients..$^{1-8}$ However, new adverse events associated with various antiretroviral regimens were soon recognized, and were collectively referred to as the lipodystrophy syndrome. ${ }^{9-11}$ When first introduced, the term HIV-associated lipodystrophy referred to alterations in the distribution of body fat and impaired glucose or lipid metabolism, and shared similar features with other less prevalent acquired and inherited forms of lipodystrophy ${ }^{12}$ and metabolic syndrome. ${ }^{13,14}$

For reasons that include a lack of standard objective diagnostic criteria and differences in study designs and study populations, determining the true prevalence of lipodystrophy in HIV-infected patients receiving antiretroviral therapy was difficult, with estimates varying in some reports from $8 \%$ to $84 \% .{ }^{15}$ It has also been demonstrated that in many patients receiving antiretroviral therapy, central fat accumulation (lipohypertrophy) is distinct etiologically and pathologically from peripheral fat changes manifesting as lipoatrophy. ${ }^{16,17}$ The former has been mostly associated with long-term exposure to PIs and the latter to nucleoside reverse transcriptase inhibitors (NRTIs).

The body composition changes associated with lipodystrophy may cause significant patient distress that could in turn interfere with adherence to antiretroviral therapy. ${ }^{18}$ Also, waist circumference and visceral adipose tissue (VAT) have been shown to be 
independent predictors of cardiovascular morbidity and mortality. ${ }^{19}$ This has led some to suggest that management of lipodystrophy could improve HIV patients' cardiovascular morbidity.

The heterogeneity of body fat abnormalities among HIVinfected patients, as well as the incompletely understood pathophysiologic mechanisms and the role of antiretroviral therapy, make management decisions difficult to devise. Therapeutic options are therefore limited. ${ }^{20}$ Antiretroviral treatment interruption has been associated with adverse outcomes, including worsening of the cardiovascular risk. ${ }^{21}$ Insulin sensitizers have been tried with limited success. ${ }^{22,23}$ Surgery - either excision or liposuction ${ }^{24}$ - or nonsurgical cosmetic approaches ${ }^{25,26}$ have also had limited and transient success.

HIV-infected patients with lipodystrophy have been found to have low levels of growth hormone $(\mathrm{GH}){ }^{27}$ Increasing endogenous GH may reduce triglycerides (TG) and overall cholesterol levels through inhibition of de novo lipogenesis and increase in fat oxidation. This has led to investigation of the manipulation of the GH axis in the management of central fat accumulation, leading to the discovery of tesamorelin (a growth hormone releasing factor). The current review focuses on the pathophysiological basis and the clinical evidence for the use of tesamorelin in the management of abdominal fat accumulation among HIV-infected patients.

\section{HIV-associated lipodystrophy}

Changes in the distribution of body fat are generally referred to as "lipodystrophy", "fat maldistribution", "fat redistribution", or "body habitus changes". Lipodystrophy is typically identified in the clinic by physical examination and patient self-report. A variety of techniques are used to measure body fat, including anthropometry, bioimpedance analysis (BI), dual-energy X-ray absorptiometry (DEXA), computed tomography (CT), magnetic resonance imaging (MRI), and ultrasonography. Each technique has limitations, however. ${ }^{28}$ Despite the proposal of a case definition for the diagnosis of HIV-associated lipodystrophy in 2003, it has not been widely adopted because it requires the use of CT and DEXA scans. ${ }^{29-31}$

HIV-infected individuals may exhibit different patterns and varying degrees of severity of changes in body fat. Two distinct types of body-fat changes are lipoatrophy (fat loss) and lipohypertrophy (fat accumulation). Lipoatrophy is characterized by subcutaneous fat depletion in the face, arms, legs, and buttocks. The preservation of lean body mass (primarily muscle) in lipoatrophy distinguishes this condition from HIV wasting syndrome, which is defined as the generalized loss of body fat and lean body mass with an involuntary weight loss of more than $10 \%$ of baseline body weight. ${ }^{15,29}$

Lipoatrophy and lipohypertrophy may manifest separately or together (ie, mixed form) in an individual, ${ }^{17,32-35}$ which suggests that peripheral lipoatrophy and central lipohypertrophy are not linked phenomena, but separate entities that develop independently. ${ }^{29}$

\section{Management of HIV-associated lipodystrophy}

At this time, no guidelines exist for the management of the body shape changes associated with HIV infection and/or antiretroviral therapy. However, a set of recommendations for managing body-fat changes have been published, only one of which is evidence-based. ${ }^{30,36,37}$ These recommendations examine several approaches: antiretroviral substitution, lifestyle modification (eg, diet and exercise), cosmetic interventions, and pharmacologic interventions. The latter have been hampered by the incompletely understood pathophysiologic mechanisms (discussed in the next section). Given the heterogeneity of the lipodystrophy syndrome, it is unsurprising that different therapeutic interventions have had various outcomes on visceral adipose tissue and peripheral adipose tissue.

\section{Antiretroviral therapy modification}

Clinical trials and observational studies have reported variable results on changes in abdominal fat following antiretroviral therapy switch. While a small study showed improvement in VAT and insulin resistance upon switching from a lopinavir/ ritonavir-containing to an atazanavir-containing regimen, ${ }^{38}$ these findings were not confirmed in a larger study of switch to atazanavir from other boosted PI. ${ }^{39}$ Replacement of a protease inhibitor with abacavir, nevirapine, or efavirenz also did not significantly change abdominal obesity. ${ }^{40,41}$ Finally, most studies did not show a significant improvement in visceral adipose tissue following a switch from thymidine-analog nucleoside reverse transcriptase inhibitor to a nonthymidine analog regimen, or to a nucleoside-sparing regimen. ${ }^{42-44}$

\section{Surgery and nonsurgical cosmetic approaches}

Surgery, either excision or liposuction, has been performed on patients with body-fat changes and may be useful in removing dorsocervical fat pads, although there may be a risk of recurrence. ${ }^{24}$ Nonsurgical cosmetic approaches include 
dermal fillers injected under the skin to restore and correct the signs of facial fat loss..$^{25,26}$ Two products, poly-L-lactic acid (Sculptra ${ }^{\mathrm{TM}}$, sanofi-aventis) and calcium hydroxylapatite (Radiesse $^{\circledR}$, Merz Aesthetics, Inc), are FDA approved for the correction of lipoatrophy in persons with HIV. ${ }^{45}$ Although both have been reported to improve facial lipoatrophy with few adverse events, findings from a small randomized, multicenter trial evaluating poly-L-lactic acid treatment using CT revealed that such treatment did not increase facial soft tissue volume overall. ${ }^{47}$ Nevertheless, patients and clinicians report that physical appearance is noticeably improved with these products.

Physical activity and diet are recommended for the management of metabolic abnormalities in the general population and have been shown to have modest, but significant reductions in waist circumference (visceral adipose tissue) among HIV-infected patients. ${ }^{48-50}$

\section{Nonantiretroviral pharmacologic interventions}

A number of agents are being investigated as potential pharmacological interventions to manage fat accumulation. The insulin sensitizers, metformin and rosiglitazone, have been reported to have conflicting effects on improving fat accumulation. Metformin may decrease visceral fat, but also subcutaneous abdominal fat, and peripheral fat. ${ }^{22}$ Rosiglitazone does not appear to improve body fat changes, ${ }^{23}$ but recent evidence suggests that it might do so among patients using thymidine-sparing regimens. ${ }^{51}$ In men with central fat accumulation, testosterone therapy significantly decreased total body, trunk, and limb subcutaneous fat, but did not change visceral fat. ${ }^{52}$

In at least some patients, the weight gain observed following antiretroviral therapy initiation might signify a return to "health" with the attendant metabolic syndrome that is very prevalent in the non-HIV population. However, it is likely that the lack of improvement in central fat accumulation that is observed in most of the studies mentioned above stems from an incomplete understanding of the pathophysiologic mechanisms underlying the changes and how to safely and effectively interfere with them.

\section{Pathophysiology of body-fat changes}

Lipodystrophy is considered to be multifactorial, resulting from the complex interaction of host factors, disease factors, and antiretroviral drug treatment. ${ }^{29}$ As mentioned above, evidence suggests that lipoatrophy and lipohypertrophy are two separate syndromes, ${ }^{17,32-35}$ the former being mostly associated with long-term exposure to PIs and the latter to NRTIs. Therefore, it is unlikely that there is a single pathophysiologic process responsible for the observed fat accumulation and loss. Several working hypotheses have been proposed to explain the development of body-fat changes. ${ }^{53-55}$ Some of the proposed pathogenic mechanisms are mediated by HIV infection itself and the host response to the infection (which could be potentiated by antiretroviral exposure), and others are linked to specific antiretroviral drugs or drug classes.

\section{Virus-host interactions and the pathogenesis of lipodystrophy}

A number of research groups have posited that immune dysregulation caused by HIV plays a role in fat redistribution. According to one model, the initial steps in the pathogenesis of body-fat changes are triggered by HIV infection and the development of a persistent inflammatory state, which is mediated by proinflammatory cytokines and the action of viral proteins with paracrine and endocrine actions on adipose tissue that alters adipocyte differentiation and function. ${ }^{54}$

Adipocyte dysfunction appears to play a key role in the development of body-fat changes, and several mechanisms have been identified that impair adipocyte differentiation and apoptosis. ${ }^{29,53-55}$ However, adipose tissue has a complex structure (populated by several different cell types) and function (regulation of fat metabolism and its own glucocorticoid metabolism). ${ }^{56}$ Adding to this complexity, adipose tissue receives hormonal and neuronal signals, and the subcutaneous and visceral compartments differ functionally, metabolically, and genetically. ${ }^{53,54,56}$ The disruption of specific pathways may be responsible for specific features and/or the severity of body habitus changes.

HIV infection may induce body fat changes by virtue of structural homology between viral and cellular proteases and/or downregulation of nuclear genes encoding mitochondrial proteins ${ }^{54}$ This might be further compounded by antiretroviral therapy.

Several other mechanisms involved in the pathogenesis of body-fat changes have been reported, including alterations in cytokines, adipokines, leptin, and adiponectin. Significantly increased levels of the pro-inflammatory cytokine tumor necrosis factor alpha (TNF $\alpha$ ) have been found in HIV patients with body-fat changes, ${ }^{57,58}$ and significantly increased mRNA expression of TNF $\alpha$ in subcutaneous adipose fat. ${ }^{59} \mathrm{TNF}-\alpha$ inhibits adipocyte differentiation and insulin sensitivity, but increases lipolysis, apoptosis, and mitochondrial toxicity. ${ }^{55}$ 
Finally, data are beginning to provide insight into the involvement of the hormonal-adipocyte axis in HIVassociated body-fat changes. Leptin and adiponectin are adipocyte hormones that play key roles in the regulation of energy homeostasis and insulin resistance. ${ }^{60}$ Changes in leptin ${ }^{61}$ and adiponectin ${ }^{62}$ levels have been observed in HIV-infected patients with lipodystrophy. The importance of the hypothalamic-pituitary axis in the pathogenesis of lipodystrophy is discussed separately in the next section.

Pathogenic mechanisms of lipodystrophy induced by different antiretroviral drug classes NRTIs induce mitochondrial toxicity. Ultrastuctural abnormalities in mitochondria and decreased mitochondrial DNA content have been found in the subcutaneous fat of HIV patients receiving antiretroviral therapy, and have been directly linked to NRTI use, particularly with stavudine and zidovudine..$^{63,64}$

PI use is thought to interfere with adipocyte maturation through inhibition of adipocyte transcription factors sterol regulatory element binding protein-1 (SREBP-1) and the peroxisome proliferators-activated receptor gamma (PPAR- $\gamma){ }^{65-67}$ This inhibition is thought to drive the increased lipolysis and peripheral fat loss, with subsequent increased triglyceride esterification and central fat accumulation.

However, recent evidence has also shown a role of NRTI in inhibition of adipocyte maturation and differentiation. Indeed, NRTIs do independently reduce PPAR- $\gamma$ expression, and continuous use of NRTIs appears to be the reason why rosiglitazone, a PPAR- $\gamma$-agonist, failed to show a benefit on HIV lipodystrophy. ${ }^{51,68}$

Finally, efavirenz (a non-nucleoside reverse transcriptase inhibitor) exerts a time-dependent decrease in expression of lipogenic transcription factor SREBP-1c, thus decreasing intracellular stores of TG. ${ }^{69}$

\section{The hypothalamic pituitary axis in HIV-infected patients with lipodystrophy}

GH is an important anabolic and lipolytic hormone produced by the somatotropic cells of the anterior pituitary gland. It is produced in a pulsatile release and its metabolic effects increased muscle and bone mass and decreased body fat - are mostly mediated by insulin-like growth factor 1 (IGF-1), which is produced in response to growth hormone at various tissue sites. $^{70}$

GH production is regulated by two stimulatory peptides - growth hormone releasing hormone (GHRH), which is produced in the hypothalamus, and ghrelin, which is produced in the gastrointestinal tract and the hypothalamus - and by the inhibitory peptide somatostatin. Its production is also modulated by inhibitory feedback exerted by IGF-1 levels.

Mean GH levels, basal GH concentrations, and GH pulse amplitude are reduced in HIV-infected men with body-fat changes receiving ART, compared with men without bodyfat changes and healthy control subjects. ${ }^{27}$ Nearly half (48\%) of the lipodystrophic patients did not achieve an adequate GH response to GHRH (using a peak GH stimulatory cutoff of $5 \mu \mathrm{g} / \mathrm{mL}$ to GHRH). In another study of HIV-infected antiretroviral-experienced men with body-fat changes, approximately $20 \%$ were found to have inadequate $\mathrm{GH}$ stimulation in response to GHRH-arginine and appeared to be functionally GH deficient. ${ }^{71}$

\section{Manipulation of the hypothalamic- pituitary axis in the management of HIV-associated lipodystrophy: GH and GHRH}

\section{Growth hormone in the management of HIV-associated lipodystrophy}

Increasing endogenous GH may reduce TGs and overall cholesterol levels through inhibition of de novo lipogenesis and increase in fat oxidation because recombinant human growth hormone (r-hGH) has been shown to reduce VAT and improve lipid levels in HIV-negative patients with GH deficiency. ${ }^{72}$ Indeed, early studies on r-hGH, given at doses ranging from 3 to $6 \mathrm{mg}$ daily for 12 to 24 weeks, reduced abdominal fat and improved the lipid profile in HIV-infected patients with abnormal fat accumulation. ${ }^{73,74}$

A double-blind, placebo-controlled trial of 245 patients was designed to further evaluate the efficacy and safety of two dosing schemes of r-hGH therapy (4 mg every day vs $4 \mathrm{mg}$ every other day) for a period of 12 weeks, as a treatment of abdominal fat among HIV-infected patients (waist-to-hip ratio, WHR) $>0.95$ and waist circumference $>88.2 \mathrm{~cm}$ in men or WHR $>0.90$ and waist circumference $>75.3 \mathrm{~cm}$ in women). The investigators also explored the efficacy of the $4 \mathrm{mg}$ every other day dose as maintenance therapy following 12-week administration of $4 \mathrm{mg}$ every day. ${ }^{75}$

Compared with placebo, VAT decreased significantly from baseline to week 12 in the daily $4 \mathrm{mg}$ dosing $(-8.6 \%$, $P<0.001)$ but not in alternate day dosing $(-4.2 \%, P=0.052)$. Trunk-to-limb fat ratio decreased significantly in both treatment groups $(P<0.001)$ compared with placebo. There were 
also modest but significant decreases in total cholesterol and nonhigh-density lipoprotein (non-HDL) cholesterol $(-4.5 \%$ and $-7.5 \%$, respectively, in daily dosing; and $-4.3 \%$ and $-6.2 \%$ in alternate day dosing).

Another randomized, placebo-controlled trial of $325 \mathrm{sub}-$ jects randomized patients to 12 -week administration of $\mathrm{r}-\mathrm{hGH}$ $4 \mathrm{mg}$ daily vs placebo; with a 24 -week maintenance phase (comparing r-hGH $2 \mathrm{mg}$ on alternate days vs placebo). ${ }^{76}$

At week 12, induction therapy resulted in decreased VAT (23.6 vs $\left.0.5 \mathrm{~cm}^{2} ; P<0.001\right)$, limb fat (20.4 vs $0.2 \mathrm{~kg}$; $P<0.001)$, and non-HDLs (213.0 vs $22.8 \mathrm{mg} / \mathrm{dL} ; P=0.023)$ compared with PL. On r-hGH induction-maintenance (baseline to week 36), patients sustained losses in VAT and trunk fat but not losses of subcutaneous fat in the abdomen or limbs.

In conclusion, a 12-week administration of supraphysiological doses of GH (2-4 mg/d) to HIV-infected patients with abdominal obesity indeed led to decreased visceral fat, but was also associated with significant GH-related adverse events, including peripheral edema, arthralgias, and increased blood glucose. ${ }^{75,76}$ The adverse effects of rhGH have been deemed to be due to the fact that direct administration of GH leads to sustained high levels, rather than the physiologic pulsating levels of the endogenous hormone.

A subsequent study showed that the administration of a low dose of GH (titrated to elevation of the insulin-like growth factor [IGF-1] to the upper quartile of physiologic levels) for 18 months resulted in significantly reduced visceral fat and truncal obesity, TGs, and diastolic blood pressure. It also led to increased 2-hour glucose levels on glucose tolerance testing. The overall safety profile was good, as adverse effects were not increased in the GH vs placebo groups. ${ }^{77}$ Importantly, the long-term (18 months) administration of r-hGH was not associated with significant changes in the carotid intima media thickness, suggesting the beneficial effects of GH on VAT and lipid levels would not necessarily translate to improved cardiovascular risk.

\section{Growth hormone releasing hormone in the management of HIV-associated lipodystrophy; tesamorelin}

The administration of GHRH is expected to generate a more physiologic pattern of GH secretion among HIVinfected patients, and avoid the aforementioned side effects resulting from supra-physiologic levels of GH. In a randomized placebo-controlled trial, ${ }^{31} \mathrm{HIV}$-infected men with increased abdominal girth $(\mathrm{WHR} \geq 0.90)$ were administered GHRH (1 mg subcutaneously twice daily) or placebo for 12 weeks. GHRH resulted in a significant increase in IGF-1 (104 ng/mL vs $6 \mathrm{ng} / \mathrm{mL}, P=0.004)$. It also increased lean body mass $(+0.9 \mathrm{~kg}$ vs $-0.3 \mathrm{~kg}, P=0.04)$ and decreased VAT $\left(-19.2 \mathrm{~cm}^{2}\right.$ vs $\left.+2.3 \mathrm{~cm}^{2} ; P=0.07\right)$, although the latter was not statistically significant. ${ }^{78}$

One important factor limiting the development of GHRH as a viable therapeutic option was its rapid degradation in vivo by the serum enzyme dipeptidylaminopeptidase 4 (DPP4). Synthetic analogs of GHRH were then investigated to render it resistant to hydrolysis by DPP4 through addition of a hydrophobic chain. This research led to the development of tesamorelin. Tesamorelin (previously known as TH9507) consists of a synthetically produced 44 amino acid sequence of human GHRH with a hexenoyl moiety attached to the tyrosine residue at the amino terminus. ${ }^{79-81}$

In preclinical studies, tesamorelin was found to be resistant to deactivation by DPP4, and markedly increased plasma levels of GH and IGF-1 after once daily dosing. ${ }^{81}$ Tesamorelin was then shown to significantly reduce trunk fat and visceral adipose tissue, but not extremity fat, and to improve the lipid profile in randomized, controlled trials. $^{82,83}$

In a dose-ranging study, 61 patients with WHR $\geq 0.94$ and $\mathrm{WC} \geq 95 \mathrm{~cm}$ (for men) and WHR $\geq 0.88$ and $\mathrm{WC} \geq 94 \mathrm{~cm}$ (for women) were randomized to receive $1 \mathrm{mg}$ or $2 \mathrm{mg}$ of tesamorelin vs placebo for 12 weeks. The $2 \mathrm{mg}$ group experienced significantly greater improvements in IGF-1 and significantly greater declines in visceral fat, TG, and cholesterol to HDL ratio (see Table 1). There was no increase in glucose levels. ${ }^{82}$

\section{Safety and efficacy of tesamorelinin HIV-associated lipodystrophy}

Two randomized controlled trials were then conducted to evaluate the safety and efficacy of tesamorelin in HIVinfected patients with abdominal obesity. ${ }^{84,85}$ Patients on a stable antiretroviral regimen for at least 8 weeks were included if they had a waist circumference $\geq 95 \mathrm{~cm}$ and a WHR $\geq 0.94$ for men, and a waist circumference $\geq 94 \mathrm{~cm}$ and a WHR $\geq 0.88$ for women. Patients were excluded if they were receiving estrogen, $\mathrm{GH}$ or related products, or had a diagnosis of pituitary disease.

Patients were randomly assigned in a ratio of $2: 1$ to receive either $2 \mathrm{mg}$ of tesamorelin or matching placebo, administered by subcutaneous injection. The studies 


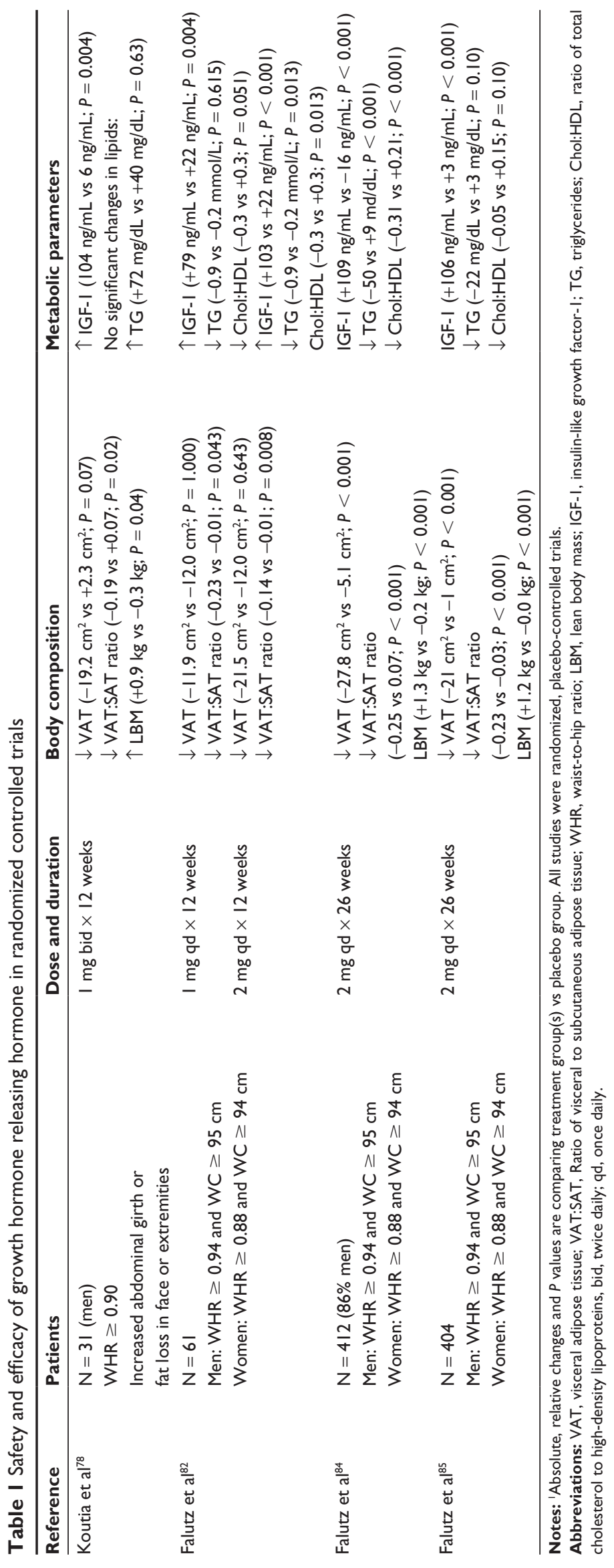


consisted of two phases: the main phase, a 26-week study period was designed to assess the primary efficacy end point, that is, reduction in VAT from baseline. It was followed by a 26 -week extension phase to evaluate long-term safety. In this phase, patients who received tesamorelin in the first phase were again randomized to receive either tesamorelin or placebo in a ratio of $3: 1$; and patients receiving placebo in the main phase were assigned to receive tesamorelin.

The primary end point was the percentage change from baseline in VAT, defined as the number of square centimeters of visceral adipose tissue and as assessed by CT scanning using an analysis of covariance (ANCOVA). Secondary end points included the ratio of subcutaneous to visceral adipose tissue (VAT:SAT), changes in patient-reported outcomes related to body image, $\mathrm{TG}$, ratio of total cholesterol to HDL, and IGF-1 levels. The first study enrolled 412 patients $(86 \%$ of whom were men). ${ }^{84}$ The second enrolled 404 patients (84\% were men).

Both studies showed concordant findings in the primary endpoint: a statistically significant decline in VAT at week 26 in the tesamorelin group compared with placebo: $-27.8 \mathrm{~cm}^{2} \mathrm{vs}+5.1 \mathrm{~cm}^{2}$ (relative difference of $-20.2 \%$ ), $P<0.001 ;-21 \mathrm{~cm}^{2} \mathrm{vs}-1 \mathrm{~cm}^{2}$ (relative difference of $-10.3 \%$ ), $P<0.001$, respectively ${ }^{84,85}$ (Table 1 ). There were also concordant declines in VAT:SAT:relative differences of $-19.8 \%, P<0.001$; and $-10.5, P<0.001$ (see Table 1 ). It is however important to note the somewhat different magnitude of effect observed in both trials. A subgroup analysis by gender presented in an FDA briefing on the drug (NDA 22-505) reported that the percent change from baseline in VAT was similar for females across studies but different for males (with larger reductions in the first study). Nonetheless, tesamorelin improved patient and physician ratings of abdominal profile in both studies.

Looking at the metabolic parameters, both studies also showed a remarkably similar increase in the level of IGF-1 (+109 $\mathrm{mg} / \mathrm{mL}$ and $+106 \mathrm{ng} / \mathrm{mL}$ in the treatment groups). ${ }^{84,85}$ There was some discrepancy between the two studies on the effect of tesamorelin on lipid levels. While TG levels in the tesamorelin group declined in both studies, this decline was only statistically significant in the first study (net difference of $-59 \mathrm{mg} / \mathrm{dL}$ relative to placebo; $P<0.001) ;{ }^{84}$ but not in the second $(-26 \mathrm{mg} / \mathrm{dL} ; P=0.10) .{ }^{85}$ Similarly, the tesamorelin-to-placebo difference in changes of total cholesterol/HDL ratio was statistically significant only in the first study $(-0.52 \mathrm{mg} / \mathrm{dL} ; P<0.001) ;{ }^{84}$ but not in the second $(-0.20 \mathrm{mg} / \mathrm{dL} ; P=0.1) .{ }^{85}$
In a pooled analysis of the two randomized controlled trials, there was a net reduction of VAT of $15.4 \%$ over 26 weeks relative to placebo. VAT decreased by $24 \mathrm{~cm}^{2}$ in patients receiving tesamorelin compared with an increase of $2 \mathrm{~cm}^{2}$ in patients receiving placebo. ${ }^{86}$ This reduction in waist circumference is almost exclusively a result of a reduction in VAT, because tesamorelin did not have a significant effect on abdominal SAT. Also, all improvements in lipid parameters were statistically significant in the tesamorelin group compared with placebo: $\mathrm{TG}(-37 \mathrm{mg} / \mathrm{dL}$ vs $+6 \mathrm{mg} / \mathrm{dL}$; $P<0.001)$; Cholesterol to HDL ratio $(-0.18$ vs +0.18 ; $P<0.001)$.

During the continuation phase of the studies, the improvement in VAT was not sustained among patients who were re-randomized to placebo after 26 weeks of therapy with tesamorelin (T-P). However, those randomized to continue tesamorelin for an additional 26 weeks (T-T) experienced a sustained reduction in VAT. Mean changes in VAT from baseline were $-32 \mathrm{~cm}^{2}$ for T-T patients and $-6 \mathrm{~cm}^{2}$ for T-P patients in the first study. ${ }^{84}$ Those changes were $-41 \mathrm{~cm}^{2}$ for T-P vs $-0 \mathrm{~cm}^{2}$ in T-P in the second study. ${ }^{85}$ Improvements in lipid profiles were also maintained only among patients who remained on tesamorelin. No significant changes in glucose parameters or immunological function were observed.

The rapid reversal of the tesamorelin effects on body fat and lipid levels upon discontinuation of therapy is probably explained by the reversal of IGF-1 increases. Among patients maintained on tesamorelin for 52 weeks, the IGF-1 levels remained at the levels achieved at week 26 , but they returned to baseline for patients switched to placebo at week $26.84,85$

Tesamorelin was found to be safe in this long-term follow-up. There were no significant changes in glucose and insulin levels over 52 weeks. None of the serious adverse events were deemed to be related to the study drug. However, an FDA briefing document on the drug (NDA 22-505) reported a statistically significant difference in the proportion of patients who developed diabetes mellitus in the tesamorelin group. Compared with placebo, odds ratios (95\% confidence intervals) for developing diabetes were 3.4 (1.3-11.5) or 3.6 (1.5-12.0) depending on whether baseline diabetes cases were excluded or not.

\section{Implications of clinical efficacy studies of tesamorelin}

In summary, tesamorelin has been shown to reduce VAT significantly, but this effect is transient and is reversed upon discontinuation of the medication. The beneficial impact of 
tesamorelin on triglyceride levels has not been consistently shown across studies.

Two main cautionary points should then be raised concerning the use of tesamorelin in HIV-infected patients with abdominal obesity:

1. The effect of tesamorelin on VAT is not sustained with discontinuation of therapy. Patients in the Phase III trials who were switched from tesamorelin to placebo after 26 weeks demonstrated a re-accumulation of VAT to near baseline levels. Chronic therapy therefore appears to be necessary to maintain the reductions in VAT, with potential exposure to long-term side effects of GH and IGF-1 stimulation. Despite the fact that GHRH administration is expected to preserve more physiologic GH secretory pulsatility and IGF-1 feedback inhibition, results from the clinical trials presented above show that patients are not free from IGF-1 related adverse events: compared with placebo, tesamorelin recipients were more likely to have an IGF-1 level above the upper limit of normal and more likely to develop diabetes.

2. Because waist circumference and VAT have been shown to be independent predictors of cardiovascular morbidity and mortality, ${ }^{19,87}$ the investigators have suggested that reduction in VAT by tesamorelin might also reduce cardiovascular risk. However, this has not yet been investigated. It is not known if VAT reduction with therapies that target the GH axis is associated with any improvements in clinical endpoints such as reduction in number or severity of cardiovascular events or cardiovascular death. Indeed, the statistically significant increase in the proportion of patients with treatmentemergent diabetes in the tesamorelin group vs placebo could adversely impact their cardiovascular risk.

The use of tesamorelin in HIV-infected patients should therefore be the result of a careful risk-to-benefit ratio analysis. One needs to make a determination whether the improvements in VAT - associated with inconsistent improvement in lipid profiles and unknown cardiovascular benefit - are worth the potential risk of chronic stimulation of the GH axis. These risks are feared to include pituitary hyperplasia or benign pituitary adenoma in an era of increased concerns over non-AIDS malignancies.

\section{Conclusion}

HIV/AIDS requires lifelong therapy with combinations of antiretroviral drugs to maximally suppress viral replication. Chronic exposure to these drugs can result in differential effects on body fat. Changes in body habitus are disfiguring, stigmatizing, and can cause psychological distress and negatively affect the quality of life. Moreover, the physical changes can lead to imperfect adherence to antiretroviral regimens, which can impact the virologic, immunologic, and clinical benefits of therapy. Regional body-fat loss and/or the accumulation associated with antiretroviral therapy therefore remain a concern and challenge in the management of HIV disease. A variety of therapeutic approaches, including insulin sensitizers and lifestyle modifications have not led to significant and sustained improvements.

The findings of low levels of GH in HIV-infected patients with lipodystrophy led to the development of tesamorelin for the management of this syndrome. Tesamorelin (previously known as TH9507) consists of a synthetically produced 44 amino acid sequence of human GHRH modified to render it resistant to enzymatic degradation and increase its half-life. It has now been shown to significantly reduce visceral adipose tissue among HIV-infected patients with central fat accumulation. However, this effect is transient and reversed upon cessation of therapy, and the long-term risk-benefit analysis of its administration is still unclear.

Currently, there are no evidence-based practice guidelines for the management of HIV-associated body-fat changes. The use of tesamorelin should therefore be evaluated in the context of multi-prong strategies to prevent, delay, or reduce these disfiguring morphologic changes due to the effect on quality of life and the potential risk for cardiovascular disease.

\section{Disclosure}

The author declares no conflicts of interest.

\section{References}

1. Brodt HR, Kamps BS, Gute P, Knupp B, Staszewski S, Helm EB. Changing incidence of AIDS-defining illnesses in the era of antiretroviral combination therapy. AIDS. 1997;11(14):1731-1738.

2. Michaels SH, Clark R, Kissinger P. Declining morbidity and mortality among patients with advanced human immunodeficiency virus infection. N Engl J Med. 1998;339(6):405-406.

3. Palella FJ Jr, Delaney KM, Moorman AC, et al. Declining morbidity and mortality among patients with advanced human immunodeficiency virus infection. HIV Outpatient Study Investigators. $N$ Engl J Med. 1998;338(13):853-860.

4. Sepkowitz KA. Effect of HAART on natural history of AIDS-related opportunistic disorders. Lancet. 1998;351(9098):228-230.

5. Detels R, Munoz A, McFarlane G, Kingsley LA, Margolick JB, Giorgi J, et al. Effectiveness of potent antiretroviral therapy on time to AIDS and death in men with known HIV infection duration. Multicenter AIDS Cohort Study Investigators. JAMA. 1998;280(17): 1497-1503. 
6. Kaplan JE, Hanson D, Dworkin MS, et al. Epidemiology of human immunodeficiency virus-associated opportunistic infections in the United States in the era of highly active antiretroviral therapy. Clin Infect Dis. 2000;30(Suppl 1):S5-S14.

7. Murphy EL, Collier AC, Kalish LA, et al. Highly active antiretroviral therapy decreases mortality and morbidity in patients with advanced HIV disease. Ann Intern Med. 2001;135(1):17-26.

8. Valdez H, Chowdhry TK, Asaad R, et al. Changing spectrum of mortality due to human immunodeficiency virus: analysis of 260 deaths during 1995-1999. Clin Infect Dis. 2001;32(10):1487-1493.

9. Carr A, Samaras K, Burton S, et al. A syndrome of peripheral lipodystrophy, hyperlipidaemia and insulin resistance in patients receiving HIV protease inhibitors. AIDS. 1998;12(7):F51-F58.

10. Lo JC, Mulligan K, Tai VW, Algren H, Schambelan M. "Buffalo hump" in men with HIV-1 infection. Lancet. 1998;351(9106):867-870.

11. Viraben R, Aquilina C. Indinavir-associated lipodystrophy. AIDS. 1998; 12(6):F37-F39.

12. Garg A. Acquired and inherited lipodystrophies. $N$ Engl J Med. 2004; 350(12):1220-1234.

13. Barbaro G. Visceral fatas target of highly active antiretroviral therapy-associated metabolic syndrome. Curr Pharm Des. 2007;13(21): 2208-2213.

14. Qiao Q, Gao W, Zhang L, Nyamdorj R, Tuomilehto J. Metabolic syndrome and cardiovascular disease. Ann Clin Biochem. 2007;44(Pt 3): 232-263.

15. Chen D, Misra A, Garg A. Clinical review 153: lipodystrophy in human immunodeficiency virus-infected patients. J Clin Endocrinol Metab. 2002;87(11):4845-4856.

16. Tien PC, Cole SR, Williams CM, et al. Incidence of lipoatrophy and lipohypertrophy in the women's interagency HIV study. J Acquir Immune Defic Syndr. 2003;34(5):461-466.

17. Jacobson DL, Knox T, Spiegelman D, Skinner S, Gorbach S, Wanke C. Prevalence of, evolution of, and risk factors for fat atrophy and fat deposition in a cohort of HIV-infected men and women. Clin Infect Dis. 2005;40(12):1837-1845.

18. Blanch J, Rousaud A, Martinez E, et al. Factors associated with severe impact of lipodystrophy on the quality of life of patients infected with HIV-1. Clin Infect Dis. 2004;38(10):1464-1470.

19. Morricone L, Donati C, Hassan T, Cioffi P, Caviezel F. Relationship of visceral fat distribution to angiographically assessed coronary artery disease: results in subjects with or without diabetes or impaired glucose tolerance. Nutr Metab Cardiovasc Dis. 2002;12(5): 275-283.

20. Cofrancesco J Jr, Freedland E, McComsey G. Treatment options for HIV-associated central fat accumulation. AIDS Patient Care STDS 2009;23(1):5-18.

21. El-Sadr WM, Lundgren JD, Neaton JD, et al. CD4+ count-guided interruption of antiretroviral treatment. $N$ Engl J Med. 2006;355(22): 2283-2296.

22. Hadigan C, Corcoran C, Basgoz N, Davis B, Sax P, Grinspoon $\mathrm{S}$. Metformin in the treatment of HIV lipodystrophy syndrome: a randomized controlled trial. JAMA. 2000;284(4):472-477.

23. Mulligan K, Yang Y, Wininger DA, et al. Effects of metformin and rosiglitazone in HIV-infected patients with hyperinsulinemia and elevated waist/hip ratio. AIDS. 2007;21(1):47-57.

24. Hultman CS, McPhail LE, Donaldson JH, Wohl DA. Surgical management of HIV-associated lipodystrophy: role of ultrasonicassisted liposuction and suction-assisted lipectomy in the treatment of lipohypertrophy. Ann Plast Surg. 2007;58(3):255-263.

25. Mest DR, Humble G. Safety and efficacy of poly-L-lactic acid injections in persons with HIV-associated lipoatrophy: the US experience. Dermatol Surg. 2006;32(11):1336-1345.

26. Silvers SL, Eviatar JA, Echavez MI, Pappas AL. Prospective, open-label, 18-month trial of calcium hydroxylapatite (Radiesse) for facial soft-tissue augmentation in patients with human immunodeficiency virus-associated lipoatrophy: one-year durability. Plast Reconstr Surg 2006;118(Suppl 3):34S-45S.
27. Rietschel P, Hadigan C, Corcoran C, et al. Assessment of growth hormone dynamics in human immunodeficiency virus-related lipodystrophy. J Clin Endocrinol Metab. 2001;86(2):504-510.

28. Behrens G, Schmidt RE. Lypodystrophy syndrome. In: Hoffmann C, Rockstroh JK, Kamps BS, editors. HIV Medicine 2006. 14th ed. Paris, France: Flying Publisher; 2006:301-316.

29. Lichtenstein KA. Redefining lipodystrophy syndrome: risks and impact on clinical decision making. J Acquir Immune Defic Syndr. 2005; 39(4):395-400.

30. Carr A. HIV lipodystrophy: risk factors, pathogenesis, diagnosis and management. AIDS. 2003;(17 Suppl 1):S141-S148.

31. Law M, Puls R, Cheng AK, Cooper DA, Carr A. Evaluation of the HIV lipodystrophy case definition in a placebo-controlled, 144-week study in antiretroviral-naive adults. Antivir Ther. 2006;11(2): 179-186.

32. Bacchetti P, Gripshover B, Grunfeld C, et al. Fat distribution in men with HIV infection. J Acquir Immune Defic Syndr. 2005;40(2): 121-131.

33. Dinges WL, Chen D, Snell PG, Weatherall PT, Peterson DM, Garg A. Regional body fat distribution in HIV-infected patients with lipodystrophy. J Investig Med. 2005;53(1):15-25.

34. Bacchetti P, Cofrancesco J, Heymsfield S, et al. Fat distribution in women with HIV infection. J Acquir Immune Defic Syndr. 2006;42(5): $562-571$.

35. Mulligan K, Parker RA, Komarow L, et al. Mixed patterns of changes in central and peripheral fat following initiation of antiretroviral therapy in a randomized trial. J Acquir Immune Defic Syndr. 2006; 41(5):590-597.

36. Grinspoon S, Carr A. Cardiovascular risk and body-fat abnormalities in HIV-infected adults. N Engl J Med. 2005;352(1):48-62.

37. Wohl DA, McComsey G, Tebas P, et al. Current concepts in the diagnosis and management of metabolic complications of HIV infection and its therapy. Clin Infect Dis. 2006;43(5):645-653.

38. Stanley TL, Joy T, Hadigan CM, et al. Effects of switching from lopinavir/ritonavir to atazanavir/ritonavir on muscle glucose uptake and visceral fat in HIV-infected patients. AIDS. 2009;23(11): 1349-1357.

39. Moyle GJ, Girard JM, Andrade J. Continuation of BID boosted PI vs switch to once-daily ATV/RTV for the management of lipodystrophy: 48 week primary analysis of the 96 week multicenter, open-label, randomized, prospective REAL study. XVII International AIDS Conference. Mexico City, Mexico; 2008.

40. Moyle GJ, Baldwin C, Langroudi B, Mandalia S, Gazzard BG. A 48-week, randomized, open-label comparison of three abacavirbased substitution approaches in the management of dyslipidemia and peripheral lipoatrophy. J Acquir Immune Defic Syndr. 2003;33(1): 22-28.

41. Fisac C, Fumero E, Crespo M, Roson B, Ferrer E, Virgili N, et al. Metabolic benefits 24 months after replacing a protease inhibitor with abacavir, efavirenz or nevirapine. AIDS. 2005;19(9):917-925.

42. Carr A, Workman C, Smith DE, et al. Abacavir substitution for nucleoside analogs in patients with HIV lipoatrophy: a randomized trial. JAMA. 2002;288(2):207-215.

43. Moyle GJ, Sabin CA, Cartledge J, et al. A randomized comparative trial of tenofovir DF or abacavir as replacement for a thymidine analogue in persons with lipoatrophy. AIDS. 2006;20(16):2043-2050.

44. Tebas $P$, Zhang J, Hafner R, et al. Peripheral and visceral fat changes following a treatment switch to a non-thymidine analogue or a nucleoside-sparing regimen in HIV-infected subjects with peripheral lipoatrophy: results of ACTG A5110. J Antimicrob Chemother. 2009; 63(5):998-1005.

45. Radiesse ${ }^{\circledR}$. Prescribing information. BioForm Medical, Inc.; 2006.

46. Sculptra ${ }^{\mathrm{TM}}$. Prescribing information. Dermik Laboratories; 2004.

47. Carey D, Baker D, Easey N, et al. Poly-L-lactic acid injections for facial lipoatrophy: a randomized, multicenter trial. 14th Conference on Retroviruses and Opportunistic Infections. Los Angeles, CA; 2007. 
48. Expert Panel on Detection E, and Treatment of High Blood Cholesterol in Adults,. Executive Summary of The Third Report of The National Cholesterol Education Program (NCEP) Expert Panel on Detection, Evaluation, and Treatment of High Blood Cholesterol in Adults (Adult Treatment Panel III). JAMA. 2001;285(19):2486-2497.

49. Fitch KV, Anderson EJ, Hubbard JL, et al. Effects of a lifestyle modification program in HIV-infected patients with the metabolic syndrome. AIDS. 2006;20(14):1843-1850.

50. Thoni GJ, Fedou C, Brun JF, et al. Reduction of fat accumulation and lipid disorders by individualized light aerobic training in human immunodeficiency virus infected patients with lipodystrophy and/or dyslipidemia. Diabetes Metab. 2002;28(5):397-404.

51. Tungsiripat M, Bejjani DE, Rizk N, et al. Rosiglitazone improves lipoatrophy in patients receiving thymidine-sparing regimens. AIDS. 2010;24(9):1291-1298.

52. Bhasin S, Parker RA, Sattler F, et al. Effects of testosterone supplementation on whole body and regional fat mass and distribution in human immunodeficiency virus-infected men with abdominal obesity. J Clin Endocrinol Metab. 2007;92(3):1049-1057.

53. Lichtenstein K, Balasubramanyam A, Sekhar R, Freedland E. HIV-associated adipose redistribution syndrome (HARS): etiology and pathophysiological mechanisms. AIDS Res Ther. 2007;4:14.

54. Giralt M, Domingo P, Guallar JP, et al. HIV-1 infection alters gene expression in adipose tissue, which contributes to HIV-1/HAARTassociated lipodystrophy. Antivir Ther. 2006;11(6):729-740.

55. Gougeon ML, Penicaud L, Fromenty B, Leclercq P, Viard JP, Capeau J. Adipocytes targets and actors in the pathogenesis of HIV-associated lipodystrophy and metabolic alterations. Antivir Ther. 2004;9(2): 161-177.

56. Kershaw EE, Flier JS. Adipose tissue as an endocrine organ. $J$ Clin Endocrinol Metab. 2004;89(6):2548-2556.

57. Vigouroux C, Maachi M, Nguyen TH, et al. Serum adipocytokines are related to lipodystrophy and metabolic disorders in HIV-infected men under antiretroviral therapy. AIDS. 2003;17(10):1503-1511.

58. Johnson JA, Albu JB, Engelson ES, et al. Increased systemic and adipose tissue cytokines in patients with HIV-associated lipodystrophy. Am J Physiol Endocrinol Metab. 2004;286(2):E261-E271.

59. Bastard JP, Caron M, Vidal H, et al. Association between altered expression of adipogenic factor SREBP1 in lipoatrophic adipose tissue from HIV-1-infected patients and abnormal adipocyte differentiation and insulin resistance. Lancet. 2002;359(9311):1026-1031.

60. Tsiodras S, Mantzoros C. Leptin and Adiponectin in the HIV Associated Metabolic Syndrome: Physiologic and Therapeutic Implications. Am J Infect Dis. 2006;2(3):141-152.

61. Nagy GS, Tsiodras S, Martin LD, et al. Human immunodeficiency virus type 1-related lipoatrophy and lipohypertrophy are associated with serum concentrations of leptin. Clin Infect Dis. 2003;36(6): 795-802.

62. Sutinen J, Korsheninnikova E, Funahashi T, Matsuzawa Y, Nyman T, Yki-Jarvinen H. Circulating concentration of adiponectin and its expression in subcutaneous adipose tissue in patients with highly active antiretroviral therapy-associated lipodystrophy. J Clin Endocrinol Metab. 2003;88(4):1907-1910.

63. Nolan D, Mallal S. Complications associated with NRTI therapy: update on clinical features and possible pathogenic mechanisms. Antivir Ther. 2004;9(6):849-863.

64. McComsey GA, Walker UA. Role of mitochondria in HIV lipoatrophy: insight into pathogenesis and potential therapies. Mitochondrion. 2004; $4(2-3): 111-118$.

65. Sekhar RV, Jahoor F, White AC, et al. Metabolic basis of HIVlipodystrophy syndrome. Am J Physiol Endocrinol Metab. 2002;283(2): E332-E337.

66. Balasubramanyam A, Sekhar RV, Jahoor F, Jones PH, Pownall HJ. Pathophysiology of dyslipidemia and increased cardiovascular risk in HIV lipodystrophy: a model of 'systemic steatosis'. Curr Opin Lipidol. 2004;15(1):59-67.
67. Pacenti M, Barzon L, Favaretto F, et al. Microarray analysis during adipogenesis identifies new genes altered by antiretroviral drugs. AIDS. 2006;20(13):1691-1705.

68. Mallon PW, Sedwell R, Rogers G, et al. Effect of rosiglitazone on peroxisome proliferator-activated receptor gamma gene expression in human adipose tissue is limited by antiretroviral druginduced mitochondrial dysfunction. J Infect Dis. 2008;198(12): 1794-1803.

69. El Hadri K, Glorian M, Monsempes C, Dieudonne MN, Pecquery R, Giudicelli $Y$, et al. In vitro suppression of the lipogenic pathway by the nonnucleoside reverse transcriptase inhibitor efavirenz in 3T3 and human preadipocytes or adipocytes. $J$ Biol Chem. 2004;279(15): 15130-15141.

70. O'Connor KO, Stevens TE, Blackman MR. Growth hormone and aging. In: Juul A, Jorgensen JOL, editors. Growth Hormone in Adults. Cambridge, UK: Cambridge University Press; 1996:323-366.

71. Koutkia P, Canavan B, Breu J, Grinspoon S. Growth hormone $(\mathrm{GH})$ responses to GH-releasing hormone-arginine testing in human immunodeficiency virus lipodystrophy. J Clin Endocrinol Metab. 2005; 90(1):32-38.

72. Bengtsson BA, Eden S, Lonn L, et al. Treatment of adults with growth hormone $(\mathrm{GH})$ deficiency with recombinant human GH. J Clin Endocrinol Metab. 1993;76(2):309-317.

73. Lo JC, Mulligan K, Noor MA, et al. The effects of recombinant human growth hormone on body composition and glucose metabolism in HIV-infected patients with fat accumulation. J Clin Endocrinol Metab. 2001;86(8):3480-3487.

74. Engelson ES, Glesby MJ, Mendez D, et al. Effect of recombinant human growth hormone in the treatment of visceral fat accumulation in HIV infection. J Acquir Immune Defic Syndr. 2002;30(4): 379-3791.

75. Kotler DP, Muurahainen N, Grunfeld C, et al. Effects of growth hormone on abnormal visceral adipose tissue accumulation and dyslipidemia in HIV-infected patients. J Acquir Immune Defic Syndr. 2004;35(3): 239-252.

76. Grunfeld C, Thompson M, Brown SJ, et al. Recombinant human growth hormone to treat HIV-associated adipose redistribution syndrome: 12 week induction and 24-week maintenance therapy. J Acquir Immune Defic Syndr. 2007;45(3):286-297.

77. Lo J, You SM, Canavan B, et al. Low-dose physiological growth hormone in patients with HIV and abdominal fat accumulation: a randomized controlled trial. JAMA. 2008;300(5):509-519.

78. Koutkia P, Canavan B, Breu J, Torriani M, Kissko J, Grinspoon S. Growth hormone-releasing hormone in HIV-infected men with lipodystrophy: a randomized controlled trial. JAMA. 2004;292(2):210-218.

79. Tomlinson B. Drug evaluation: tesamorelin, a synthetic human growth hormone releasing factor. Curr Opin Investig Drugs. 2006;7(10): 936-945.

80. Wang Y, Tomlinson B. Tesamorelin, a human growth hormone releasing factor analogue. Expert Opin Investig Drugs. 2009;18(3): 303-310.

81. Ferdinandi ES, Brazeau P, High K, Procter B, Fennell S, Dubreuil P. Non-clinical pharmacology and safety evaluation of TH9507, a human growth hormone-releasing factor analogue. Basic Clin Pharmacol Toxicol. 2007;100(1):49-58.

82. Falutz J, Allas S, Kotler D, et al. A placebo-controlled, dose-ranging study of a growth hormone releasing factor in HIV-infected patients with abdominal fat accumulation. AIDS. 2005;19(12):1279-1287.

83. Falutz J, Allas S, Blot K, et al. Effects of TH9507, a growth hormone releasing factor analog, on HIV-associated abdominal fat accumulation: A multicenter, double-blind placebo-controlled trial with 412 randomized patients. 14th Conference on Retroviruses and Opportunistic Infections (CROI). Los Angeles, CA; 2007.

84. Falutz J, Allas S, Blot K, Potvin D, Kotler D, Somero M, et al. Metabolic effects of a growth hormone-releasing factor in patients with HIV. N Engl J Med. 2007;357(23):2359-2370. 
85. Falutz J, Potvin D, Mamputu JC, Assaad H, Zoltowska M, Michaud SE, et al. Effects of tesamorelin, a growth hormone-releasing factor, in HIV-infected patients with abdominal fat accumulation: a randomized placebo-controlled trial with a safety extension. J Acquir Immune Defic Syndr. 2010;53(3):311-322.

86. Falutz J, Mamputu JC, Potvin D, et al. Effects of tesamorelin (TH9507), a growth hormone-releasing factor analog, in human immunodeficiency virus-infected patients with excess abdominal fat: a pooled analysis of two multicenter, double-blind placebo-controlled phase 3 trials with safety extension data. J Clin Endocrinol Metab. 2010;95(9):4291-4304.
87. Nakamura T, Kobayashi H, Yanagi K, et al. Importance of intraabdominal visceral fat accumulation to coronary atherosclerosis in heterozygous familial hypercholesterolaemia. Int J Obes Relat Metab Disord. 1997;21(7):580-586.

\section{Publish your work in this journal}

HIV/AIDS - Research and Palliative Care is an international, peerreviewed open-access journal focusing on advances in research in HIV, its clinical progression and management options including antivira treatment, palliative care and public healthcare policies to contro viral spread. The journal welcomes original research, basic science, clinical \& epidemiological studies, reviews \& evaluations, expert opinion \& commentary, case reports \& extended reports. The manuscript management system is completely online and includes a very quick and fair peer-review system. Visit http://www.dovepress.com/ testimonials.php to read real quotes from published authors.

Submit your manuscript here: http://www.dovepress.com/hivaids---research-and-palliative-care-journal 